\title{
Terraplanismo, Ludwik Fleck e o mito de Prometeu ${ }^{+*}$
}

André Ferrer Pinto Martins ${ }^{1}$

Departamento de Práticas Educacionais e Currículo

Universidade Federal do Rio Grande do Norte

Natal - RN

\section{Resumo}

Objetivamos, nesse trabalho, analisar o movimento terraplanista com a utilização do referencial oferecido pela teoria do conhecimento de Ludwik Fleck (1896-1961). O terraplanismo é um fenômeno social que pode ser associado à problemática da chamada "pós-verdade". A crença de que a Terra é plana e de que o conhecimento científico construido historicamente a esse respeito está errado vem, aparentemente, crescendo no Brasil e no mundo. Um reflexo disso foi a realização, no final de 2019 em São Paulo, da primeira Convenção Nacional da Terra Plana. Tomando como base os discursos proferidos nas diversas palestras ocorridas durante esse evento, esse trabalho, de cunho qualitativo, buscou identificar elementos característicos do pensamento desse grupo. Por meio da análise das notas de campo de observação, identificou-se um conjunto prévio de seis características do discurso terraplanista, detalhadas no corpo do trabalho. Em seguida, procedeu-se à análise desse material a partir do referencial oferecido pela epistemologia de Fleck. Especificamente, os conceitos fleckianos de estilo de pensamento, coletivo de pensamento, circulação intracoletiva e intercoletiva de ideias, círculos esotérico e exotérico, acoplamentos ativo e passivo, harmonia das ilusões e protoideias mostraram-se úteis na caracterização e interpretação do movimento terraplanista. Ao final, tecemos algumas reflexões que, a nosso ver, deveriam ser objeto de atenção da área de ensino de ciências/física no que diz respeito a essa temática, em particular, a necessidade de estarmos atentos a esse

\footnotetext{
${ }^{+}$Flat Earth movement, Ludwik Fleck and the myth of Prometheus

* Recebido: maio de 2020. Aceito: outubro de 2020.

${ }^{1}$ E-mail: aferrer34@yahoo.com.br
} 
fenômeno social, problematizando-o. Defendemos que um ensino crítico da ciência e o respeito a pontos de vista diversos aos cientificamente aceitos não deve implicar em uma desvalorização do pensamento cientifico.

Palavras-chave: Ludwik Fleck; Epistemologia; Estilo de Pensamento; Coletivo de Pensamento; Terraplanismo.

\begin{abstract}
In this work, we aim to analyze the Flat Earth movement using the framework offered by the theory of knowledge of Ludwik Fleck (18961961). The Flat Earth movement is a social phenomenon that can be associated with the so-called "post-truth" issue. The belief that the Earth is flat and that the scientific knowledge historically constructed in this regard is wrong is apparently growing in Brazil and in the world. A reflection of this was the realization, at the end of 2019 in São Paulo, of the first Flat Earth National Convention. Based on the speeches given in the various lectures that took place during this event, this qualitative study sought to identify characteristic elements of this group's thinking. Through the analysis of the observation field notes, we identified a previous set of six characteristics of the Flat Earth supporters' speech, detailed in the body of the work. Then, this material was analyzed based on the theoretical framework offered by Fleck's epistemology. Specifically, the fleckian concepts of thought style, thought collective, intracollective and intercollective circulation of ideas, esoteric and exoteric circles, active and passive coupling, harmony of illusions and protoideas proved to be useful in the characterization and interpretation of the Flat Earth movement. At the end, we make some reflections that, in our view, should be the object of attention in the area of science/physics teaching in regard to this theme, in particular, the need to be aware of this social phenomenon, problematizing it. We argue that a critical teaching of science and the respect for points of view different from those scientifically accepted should not imply a devaluation of scientific thinking.
\end{abstract}

Keywords: Ludwik Fleck; Epistemology; Thought Style; Thought Collective; Flat Earth Movement. 


\section{Introdução}

"Pós-verdade" é um termo polissêmico que vem sendo objeto de debates no meio acadêmico e na sociedade em geral, nos últimos anos. Eleita como a "palavra do ano" pelo dicionário Oxford em 2016, ganhou notoriedade na mídia em função de uma série de eventos no campo político e social, com destaque para a eleição de Donald Trump nos Estados Unidos e para a saída do Reino Unido da comunidade europeia (conhecida como "Brexit"). Ambos os eventos foram marcados pela manipulação deliberada da opinião pública e pela disseminação em massa de notícias falsas (fake news), aspectos intimamente vinculados à noção de pósverdade.

Segundo o dicionário Oxford, o termo pós-verdade é "relativo a, ou denota circunstâncias nas quais fatos objetivos são menos influentes em moldar a opinião pública do que apelos à emoção e crença pessoal" (OXFORD DICTIONARY, 2016, tradução nossa 2). Embora possamos questionar e problematizar essa definição - como o fazem, aliás, Lima et al. (2019) em um aprofundado e consistente trabalho baseado nas ideias de Bruno Latour -, principalmente devido à presença da expressão "fatos objetivos", a perspectiva de que a opinião pública seja moldada com forte apelo às emoções, crenças pessoais e afetos nos parece ser o cerne da noção de pós-verdade.

Nessa direção, a problemática relativa à pós-verdade transcende o campo do jogo de forças políticas e se imiscui no tecido complexo da circulação de ideias na sociedade, potencializado pelas redes sociais, dando origem a fenômenos variados, como o revisionismo histórico, a negação do aquecimento global, movimentos anti-vacinas e o terraplanismo. Boa parte desses fenômenos sociais compartilham certa oposição à ciência, que pode variar de moderada a agressiva.

Nosso foco, nesse trabalho, é o movimento terraplanista cuja defesa, essencialmente, é a de que "a Terra é plana", ou seja, que o conhecimento estabelecido pela comunidade científica a respeito do formato do nosso planeta está errado (além da questão do formato, essa posição traz consequências, é claro, para muitos outros aspectos estabelecidos na física e na astronomia, como, por exemplo, os movimentos da Terra, sua posição relativa a outros astros etc.).

Embora o terraplanismo (TP) tenha adquirido caráter mundial, há certo protagonismo da Flat Earth Society, sediada nos Estados Unidos ${ }^{3}$. Três conferências internacionais voltadas

\footnotetext{
2 Outra definição ligeiramente diferente é encontrada no sítio do Oxford Learners's Dictionaries: "relativo a circunstâncias nas quais as pessoas respondem mais a sentimentos e crenças do que a fatos" (OXFORD LEARNERS'S DICTIONARIES, 2020, tradução nossa).

${ }^{3}$ Site oficial: https://www.tfes.org/. Facebook: https://www.facebook.com/FlatSoc/. Aparentemente foi criada algo como uma "Wiki" desse grupo (não vinculada à Wikipedia): https://wiki.tfes.org/The_Flat_Earth_Wiki, que traz informações sobre a Sociedade (https://wiki.tfes.org/Flat_Earth_Society).
} 
ao tema já foram realizadas ${ }^{4}$. No Brasil, o movimento terraplanista também está presente, marcadamente em redes sociais como o Youtube. Uma pesquisa de meados de 2019 apontou que cerca de $7 \%$ dos brasileiros acreditam que a Terra seja plana ${ }^{5}$. Ao final daquele ano, São Paulo (SP) sediou a primeira Convenção Nacional da Terra Plana - FLAT CON BRASIL 2019, que reuniu durante um dia inteiro a "comunidade" terraplanista nacional ${ }^{6}$.

A imagem social e o status atual do movimento terraplanista são relativamente dúbios e incertos. Se, por um lado, a relativa curiosidade das pessoas a esse respeito e a atenção de parte da imprensa, quem sabe, tenha dado certo destaque a ele (ainda que como "factóide"), por outro lado, mais recentemente, o TP tem sido associado à ignorância, irreflexão, pensamento ultrapassado e acrítico. O termo "terraplanismo" ganhou conotação depreciativa, principalmente, quando vinculado a questões amplas da política nacional e da vida social $^{7}$.

A relação de desdém e desprezo que parte da sociedade e da comunidade científica nutrem pelo terraplanismo justificam, em associação ao fato de se tratar de fenômeno recente, a relativa ausência de estudos na literatura especializada, muito embora comecem a surgir trabalhos que buscam analisar o movimento terraplanista (certamente esse número especial do Caderno Brasileiro de Ensino de Física vem a contribuir no preenchimento dessa lacuna). Nessa linha, encontramos o artigo de Melo, Passos e Salvi (2020), que analisaram publicações na página do Twitter da Flath Earth Society a partir dos referenciais de Feyerabend, Latour e Stengers, bem como de outras referências voltadas à caracterização das chamadas "teorias da conspiração". Pivaro (2019) utilizou-se do referencial de Vigotski em sua análise do fórum online da Flath Earth Society, em um trabalho apresentado no último ENPEC. Uma vez que o terreno próprio de disseminação do terraplanismo são as redes sociais, é sintomático que comecem a surgir trabalhos em outras áreas, como, por exemplo, a de comunicação e estudos de mídia, como o artigo de Albuquerque e Quinan (2019), que também se referem à cultura das teorias de conspiração e analisam um canal do Youtube voltado ao terraplanismo.

Mesmo diante de um número reduzido de estudos acadêmicos, já é possível perceber a multiplicidade de referenciais que serão trazidos e que podem contribuir no entendimento do terraplanismo, bem como das suas relações com a problemática mais ampla da pósverdade e as consequências para o ensino das ciências. Partimos, então, da seguinte pergunta:

4 Página oficial da última Conferência, realizada em novembro de 2019 no Texas (EUA): $<$ https://flatearthconference.com/about/about-us/>. Nesse site há a informação de que a "2019 Flat Earth International Conference" (FEIC) não tem qualquer afiliação com a Flat Earth Society.

$5<$ https://www1.folha.uol.com.br/ciencia/2019/07/7-dos-brasileiros-afirmam-que-terra-e-plana-mostra-pesquisa. shtml?aff_source=56d95533a8284936a374e3a6da3d7996>.

6 A página dessa "comunidade" no Facebook pode ser acessada em: https://www.facebook.com/Terra-PlanaOficial-2329665173920284/.

7 Basta ver, por exemplo, as recentes discussões em torno da pandemia da COVID-19, quando houve uma retomada de certa defesa da ciência. Posturas anticientíficas e pessoas que as defendem são taxadas, frequentemente nesse contexto, como "terraplanistas". 
avaliando-o como fenômeno social, seria oportuno analisar o terraplanismo a partir de um referencial próprio da epistemologia?

Considerando a perspectiva de Ludwik Fleck (1896-1961) como potencialmente frutífera para atacarmos o problema em foco, objetivamos, nesse trabalho, analisar o movimento terraplanista com a utilização do referencial fleckiano. Buscaremos trazer conceitos da teoria do conhecimento ${ }^{8}$ de Fleck na tentativa de lançar luzes sobre esse movimento, avaliando sua maior ou menor pertinência e sua força teórica interpretativa. Focalizaremos, especificamente, o movimento terraplanista nacional em suas manifestações durante a primeira Convenção Nacional da Terra Plana. Faremos, ao final, algumas reflexões que, a nosso ver, deveriam ser objeto de atenção da área de ensino de ciências/física no que diz respeito a essa temática.

\section{Fleck em poucas palavras}

Trazemos, nessa seção, o referencial teórico oferecido por Ludwik Fleck (18961961).

Não é a intenção desse trabalho - e nem seria viável - apresentarmos aos leitores a perspectiva de Fleck de modo amplo e detalhado. $\mathrm{O}$ fato desse autor haver se tornado mais conhecido na área de ensino de ciências, nas últimas décadas, também nos desobriga desta tarefa e permite que tragamos, apenas, alguns dos conceitos centrais de sua teoria do conhecimento. Uma revisão de trabalhos da literatura especializada (no caso, dissertações e teses, em nível nacional) que se utilizam do referencial fleckiano pode ser encontrada em Lorenzetti, Muenchen e Slongo (2018) ${ }^{9}$. Nossa análise se utiliza da principal obra de Fleck, Gênese e desenvolvimento de um fato cientifico (FLECK, 2010), originalmente escrita em 1935, e de seus sete artigos sobre epistemologia, organizados e republicados em Cohen e Schnelle (1986).

Fleck foi um médico polonês cuja produção intelectual se estende, grosso modo, da década de 1920 até 1960. Especializado em microbiologia e no diagnóstico de várias doenças, dentre elas o tifo, trabalhou em diversos laboratórios e centros de pesquisa de sua cidade natal (Lwów, atualmente na Ucrânia) antes da segunda guerra mundial. Judeu, sofreu perseguição pelos alemães e foi enviado ao gueto de Lwów e, posteriormente, a campos de concentração. Sobreviveu à guerra, justamente, pelo seu conhecimento da medicina, uma vez que foi

\footnotetext{
8 Nesse trabalho utilizaremos o termo 'epistemologia' como sinônimo de 'teoria do conhecimento' em Fleck. Notemos que a obra desse autor também costuma ser situada no campo da "sociologia do conhecimento", dada a ênfase de Fleck no caráter social, histórico e coletivo do processo de conhecimento, como veremos adiante.

${ }^{9}$ Há uma concentração de trabalhos sobre Fleck na Universidade Federal de Santa Catarina (UFSC), fruto, sem dúvida, da influência do professor Demétrio Delizoicov, que atuou como orientador de muitos deles. Um número especial do Caderno Brasileiro de Ensino de Física, de 2002, destinado à reflexão epistemológica, trazia um artigo sobre Fleck de Delizoicov e colaboradores (DELIZOICOV et al., 2002), tendo sido responsável por parte da divulgação do pensamento desse autor entre nós. Recentemente, tivemos também a oportunidade de produzir um trabalho sobre a obra de Fleck (ver: Martins, no prelo).
} 
encarregado de produzir uma vacina contra o tifo. Com o fim dos combates e a libertação da Europa pelas tropas russas e pelos aliados, Fleck voltou a atuar como pesquisador e a ocupar cargos em universidades, laboratórios etc. ${ }^{10}$.

Sua produção no campo da epistemologia se deu de modo periférico e nas suas "horas de lazer". Sua obra principal (o livro de 1935) não foi reconhecida, à época, permanecendo praticamente ignorada por décadas. A literatura especializada costuma elencar várias razões para isso, como o fato de haver sido publicada em alemão, na Suíça, por uma editora desconhecida e com uma tiragem pequena, assim como haver recebido poucas resenhas críticas, a maioria em periódicos da área médica. A "redescoberta" de Fleck se deu apenas na década de 1960, com a menção à sua obra no Prefácio de $A$ estrutura das revoluções cientificas de Thomas S. Kuhn. A partir de então, surgiram outros estudos e Gênese e desenvolvimento de um fato científico ganhou traduções em diversas línguas.

Fleck compreende que a epistemologia só tem sentido se trouxermos as perspectivas histórica e social. O "conhecimento é o produto social por excelência" (FLECK, 2010, p. 85) e "Qualquer teoria do conhecimento que não leva em conta esse condicionamento social de todo conhecimento é uma brincadeira" (FLECK, 2010, p. 86). Em Gênese, Fleck se utiliza da história da ciência (história da sífilis e da reação de Wassermann) para dela depreender ensinamentos para a epistemologia.

Afirma que devemos ir além dos tradicionais dois polos da relação epistemológica (sujeito e objeto), considerando um terceiro elemento: o estado do saber. Não há observação neutra, todo o olhar é direcionado. A ideia de que qualquer observação já parte de certas condições dadas e de que "aprendemos a ver" de certos modos que são frutos da educação e da tradição em que estamos inseridos - e, portanto, são coletivos - está no cerne do conceito fleckiano de estilo de pensamento. Para ele, não vemos para conhecer, mas conhecemos para ver (FLECK, 1986a).

O estilo de pensamento (EP) caracteriza-se por esse "olhar direcionado", por certa disposição mental que nos leva à identificação da forma imediata. Um EP define o que "não pode ser pensado de outra maneira”. Nas palavras de Fleck:

O estilo de pensamento, assim como qualquer estilo, consiste numa determinada atmosfera (Stimmung) e sua realização. Uma atmosfera (Stimmung) possui dois lados inseparáveis: ela é a disposição (Bereitschaft) para um sentir seletivo e para um agir direcionado correspondente. Ela gera as formas de expressão adequadas: religião, ciência, arte, costumes, guerra etc, de acordo com a predominância de certos motivos coletivos e dos meios coletivos investidos. Podemos, portanto, definir o estilo de pensamento como percepção direcionada em conjunção com o processamento correspondente no plano mental e objetivo. Esse estilo é marcado por características comuns dos problemas, que interessam a um coletivo de pensamento; dos julgamentos, que considera como evidentes e dos métodos, que

\footnotetext{
${ }^{10}$ Para uma biografia de Fleck, ver: a Introdução de Fleck (2010) e, especialmente, a Parte I de Cohen e Schnelle (1986).
} 
aplica como meios do conhecimento. É acompanhado, eventualmente, por um estilo técnico e literário do sistema do saber (FLECK, 2010, p. 149, grifos do autor).

A vinculação histórica de pensamentos na constituição de um EP é apontada por Fleck e vincula-se a uma das noções trazidas por esse autor: a de protoideias (ou pré-ideias). Elas seriam ideias do passado que guardam ligações evolutivas com ideias atuais. Fleck cita, por exemplo, o caso do atomismo da antiguidade grega e a noção do sangue "corrompido" dos sifilíticos. Destaca que:

As protoideias devem ser consideradas como pré-disposições histórico-evolutivas (entwicklungsgeschichliche Anlagen) de teorias modernas e sua gênese deve ser fundamentada na sociologia do pensamento (denksozial) (FLECK, 2010, p. 66, grifos do autor).

Ao importante conceito fleckiano de EP encontra-se vinculado, diretamente, o conceito de coletivo de pensamento $(\mathrm{CP})$ que Fleck define dessa maneira ${ }^{11}$ :

Se definirmos o 'coletivo de pensamento' como a comunidade das pessoas que trocam pensamentos ou se encontram numa situação de influência recíproca de pensamentos, temos, em cada uma dessas pessoas, um portador do desenvolvimento histórico de uma área de pensamento, de um determinado estado do saber e da cultura, ou seja, de um estilo específico de pensamento (FLECK, 2010, p. 82, grifos do autor).

O CP é, portanto, o portador comunitário do EP. Fleck destaca que a introdução num dado estilo de pensamento se dá por meio de uma "suave coação", uma "condução para dentro" que tem características dogmáticas e, até certo ponto, autoritárias. O aprendiz aprende a ver como o iniciado, criando-se com o tempo, no interior do estilo, aquilo que o autor denomina de "harmonia das ilusões", quando a percepção, o sentir e o agir direcionados tornam-se hábitos inquestionáveis. Um membro de um $\mathrm{CP}$, em geral, não tem consciência disso. Sua forma particular de ver lhe parece natural.

Em Gênese, ao abordar a formação do especialista no caso da reação de Wassermann, Fleck afirma:

Toda introdução didática numa área envolve um tempo em que predomina um ensino puramente dogmático. Prepara-se um intelecto para uma área, acolhe-se o mesmo num mundo fechado, dá-se a ele uma espécie de bênção de iniciação. Se essa iniciação passou a ser tão difundida como, por exemplo, no caso da introdução nos fundamentos da física, ela se torna tão natural que as pessoas se esquecem de tê-la recebido, uma vez que não têm contato com nenhum não iniciado (FLECK, 2010, p. 99).

\footnotetext{
${ }^{11}$ Em Gênese essa definição de CP surge antes da citação que fizemos do EP, mas isso se deve ao fato de Fleck ir construindo um entendimento de EP ao longo de toda a obra.
} 
Mas os coletivos não são formações homogêneas, pois têm uma estrutura. Quanto a isso, Fleck introduz os conceitos de círculo esotérico e círculo exotérico. Cada formação de pensamento contém uma espécie de "núcleo central" de "especialistas", mais fechado, em torno do qual situam-se outros sujeitos que compartilham do estilo de pensamento de modo indireto. Nas palavras de Fleck:

(...) em torno de qualquer formação do pensamento, seja um dogma religioso, uma ideia cientifica ou um pensamento artístico, forma-se um pequeno círculo esotérico e um círculo exotérico maior de participantes do coletivo de pensamento. Um coletivo de pensamento consiste em muitos desses círculos que se sobrepõem, e um indivíduo pertence a vários círculos exotéricos e a poucos círculos esotéricos (FLECK, 2010, p. 157).

Podemos pensar que, por exemplo, em relação ao "EP da física", os pesquisadores em física estariam no círculo esotérico e os professores de física da educação básica situar-seiam no círculo exotérico.

Embora Fleck não teorize especificamente sobre a linguagem, ela tem papel fundamental em sua epistemologia. Os pensamentos circulam na sociedade entre os diversos coletivos. Esse tráfego (ou circulação) de ideias pode se dar de duas maneiras, basicamente, segundo Fleck. Há o tráfego interno a um certo coletivo, que ele denomina de tráfego intracoletivo, que tende a reforçar o próprio EP. Tanto a comunicação entre especialistas, por exemplo, quanto a circulação de ideias do centro à periferia (e vice-versa) de um mesmo coletivo identificam esse tipo de tráfego intracoletivo.

Mas há também a circulação de ideias entre coletivos distintos, denominada de tráfego intercoletivo. Nesse caso, é mais comum o surgimento do que Fleck caracteriza de "desvios de significado", quando ideias sofrem deslocamentos de sentido e surgem "mal entendidos". Esses, por sua vez, teriam uma função positiva, segundo Fleck, contribuindo para mudanças nos pensamentos relacionadas às transformações dos EPs. Quanto mais diferentes forem dois EPs, menor seria esse tráfego intercoletivo e menor a possibilidade de diálogo.

Outros conceitos muito importantes em Fleck são os de acoplamento ativo e acoplamento passivo. Os primeiros dizem respeito à parte coletiva do conhecimento, àquilo que, grosso modo, é trazido pelos sujeitos ao processo de produção de conhecimento. Já os acoplamentos passivos referem-se aos "resultados inevitáveis" e não seriam explicados nem psicologicamente, nem historicamente. Segundo Fleck:

Conhecer, portanto, significa, em primeiro lugar, constatar os resultados inevitáveis sob determinadas condições dadas. Estas condições correspondem aos acoplamentos ativos, formando a parte coletiva do conhecimento. Os resultados inevitáveis equivalem aos acoplamentos passivos e formam aquilo que é percebido como realidade objetiva. $O$ ato da constatação compete ao indivíduo (FLECK, 2010, p. 83). 
O exemplo trazido por Fleck em Gênese, a esse respeito, é o da massa dos elementos químicos. Se adotarmos um valor arbitrário para a massa atômica do oxigênio (acoplamento ativo), por exemplo, o valor da massa atômica do hidrogênio estaria determinado (acoplamento passivo), pois o valor relacional entre as massas seria um elemento passivo do saber $^{12}$

Os conceitos de acoplamento ativo e passivo estão relacionados ao processo de desenvolvimento e transformação dos EPs. Para Fleck, as teorias passam por uma "fase clássica", marcada pela harmonia das ilusões, e por "uma fase de complicações, quando as exceções se manifestam" (FLECK, 2010, p. 71). A consciência de tais complicações pelos membros do EP pode levar à procura de soluções que propiciem a transformação do estilo.

$O$ fato (científico) surge então, para Fleck, incialmente como uma coerção de pensamento, uma oposição à vontade livre do pensamento. Ele é resultado da articulação entre as partes ativas e passivas do saber e só pode ser percebido enquanto tal sob o pano de fundo de um EP. Não há fato fora de um EP, pois ele é, no fundo, uma "relação de conceitos conforme o estilo de pensamento" (FLECK, 2010, p. 132).

É oportuno sinalizar o vínculo e a imbricação entre todos os conceitos apresentados. Haveria mais elementos da teoria do conhecimento de Fleck a trazermos aqui para caracterizá-la de modo mais completo. Mas, para os nossos propósitos e considerando as limitações de espaço, acreditamos ser suficiente aquilo que foi exposto nessa seção.

\section{A FLAT CON BRASIL 2019 e a metodologia da pesquisa ${ }^{13}$}

Realizada em um teatro no bairro da Liberdade, em São Paulo (SP), em 10 de novembro de 2019, a primeira Convenção Nacional da Terra Plana ${ }^{14}$ contou, segundo os organizadores do evento, com a participação de cerca de 400 pessoas. Dez palestrantes se revezaram no palco ao longo do dia. A quase totalidade deles era formada por Youtubers e detinha um canal específico nessa rede social.

A imprensa foi proibida de adentrar ao salão principal para gravar ou filmar as palestras, limitando-se a fazer entrevistas e tirar fotos na parte externa. Houve, no entanto, filmagem das palestras por parte da organização do evento, que as disponibilizou em um canal do Youtube alguns meses depois ${ }^{15}$. Aos participantes registrados no evento, também não foi permitida a realização de filmagens, mas apenas de registro fotográfico.

\footnotetext{
12 Os conceitos de acoplamento ativo e passivo representam um aspecto bastante inovador da obra de Fleck que pode ser relacionado ao debate realismo - antirrealismo e ao "agenciamento" da natureza. Está no centro da discussão sobre o relativismo epistemológico. Mas esse não é o espaço para aprofundamento desse tema.

13 Essa seção e a próxima, especificamente, fizeram parte de um trabalho submetido a evento da área de ensino de ciências (Martins, 2020) e, dadas suas características eminentemente descritivas, contêm trechos semelhantes a outros, presentes no trabalho citado.

14 Tanto o site oficial quanto a página do evento no Facebook foram desativados, aparentemente.

$15<$ https://www.youtube.com/channel/UCrtiLhYAY4Up_YD3w0DR_7w/videos>.
} 
Como participante, o autor desse trabalho construiu um "diário de campo" de observação, anotando tudo o que foi possível ao longo das palestras. A ideia foi a de registrar o mais fielmente possível os aspectos centrais daquilo que estava sendo exposto sem, contudo, promover qualquer tipo de "análise" naquele momento. Embora saibamos que uma atitude ou postura completamente neutra seja impossível, a intenção foi a de, deliberadamente e desde o início, assumir uma postura de "observador isento", cuja finalidade era apenas a do registro escrito. Dadas tais características, esse estudo se insere no contexto de pesquisas de cunho qualitativo (LÜDKE; ANDRE, 1986; ALVES-MAZZOTTI; GEWANDSZNAJDER, 1999) e assemelha-se ao que Mayring (2002) denomina de "pesquisa de campo", com aspectos de observação naturalística.

A partir do conteúdo desse diário de campo procurou-se identificar, em cada uma das palestras: o tema central; as principais ideias defendidas, e os argumentos utilizados. Esses elementos foram dispostos, inicialmente, em um quadro para cada palestra. Temas e ideias recorrentes também foram identificados. Em seguida, procedemos ao agrupamento de ideias semelhantes, chegando a um conjunto de elementos característicos que sugerem uma primeira aproximação ao pensamento terraplanista, tal qual exposto no evento ${ }^{16,17}$. Tal caracterização será apresentada na seção a seguir.

\section{O pensamento terraplanista}

Nossa análise do conteúdo das palestras proferidas durante a FLAT CON BRASIL 2019 identificou um conjunto de seis características do discurso terraplanista, apontadas na lista a seguir:

1) O terraplanismo (TP) estaria fora de um "sistema" que esconde a verdade.

2) Estabelecimento de uma relação bipolar com o conhecimento científico.

3) Uso "particularizado" de termos e conceitos da ciência.

4) Seletividade no uso de dados e informações.

5) Vínculo com questões de natureza religiosa.

\footnotetext{
16 Em nossa análise, adotamos a perspectiva oferecida pela análise textual discursiva (ATD) (MORAES, 2003; MORAES; GALIAZZI, 2011), mas com algumas ressalvas. Foram criadas unidades de análise (seguindo o que os autores denominam de "processo de unitarização"), com posterior estabelecimento de relações entre essas unidades de análise (de modo semelhante ao "processo de categorização" da ATD) e a criação do "novo emergente" (que corresponde, grosso modo, às seções seguintes de nosso trabalho). Essas três etapas formam o $1^{\circ}$ ciclo da ATD. No entanto, optamos por não denominar de "categorias" o agrupamento de nossas unidades de análise, uma vez que entendemos que esse termo carrega a ideia de exclusão mútua - o que não é o caso -, apesar de Moraes (2003) discutir a questão e considerar que as categorias não são necessariamente excludentes. Não foi realizado, em nossa análise, o chamado "processo auto-organizado" (4⿳a etapa / $2^{\circ}$ ciclo) da ATD.

17 Apenas o material escrito do diário de campo foi considerado na análise, uma vez que os vídeos das palestras estavam indisponíveis até a finalização desse processo. No entanto, com a disponibilização posterior desse material (ver nota 15, supra), o seu conteúdo foi cotejado com nossa análise prévia para eventuais ajustes, correções e acréscimos. Essa revisitação não trouxe quaisquer modificações significativas, mas, apenas, alguns exemplos ilustrativos para a nossa descrição do discurso terraplanista (seção seguinte).
} 
6) Crítica à escola e ao ensino de ciências.

Sem perder de vista que se tratam de características gerais e que há sobreposição entre elas, passemos a uma descrição de cada item.

Diversos palestrantes fazem menção a um "sistema" que esconde das pessoas (aparentemente, de modo deliberado) a "verdade". Esse sistema é identificado com diversos setores e práticas sociais, tais como a política, a mídia, a ciência, a escola. A NASA (agência espacial norte-americana) é citada diversas vezes como fazendo parte desse sistema e, em particular, propagadora de falsas ideias como, por exemplo, a de que o ser humano já foi à Lua.

O sistema tende a manter o status quo (principalmente em relação ao conhecimento estabelecido e veiculado nas escolas). Aqueles que duvidam ou questionam o que diz o sistema são perseguidos e/ou ridicularizados, o que seria o caso dos defensores do TP (em uma das palestras, inclusive, foi informado que pessoas estariam sendo presas - e até assassinadas - em outros países por acreditarem na Terra plana). Daí que o "encontro" com o TP seja relatado, por muitos, como uma busca por uma verdade escondida, havendo uma valorização da ação individual nessa busca genuína por conhecimento. Afirmou-se, por exemplo, que devemos crer no que podemos observar e medir por nós mesmos.

Não é à toa que a imprensa foi impedida de registrar o evento. Afinal, eles fazem parte "do sistema". O próprio local de realização do evento só foi divulgado aos inscritos na noite anterior, e falou-se em "tentativa de sabotagem" da FLAT CON. Nesse sentido, o TP acaba propagando um discurso do tipo "nós contra eles" e criando um sentimento de comunidade, de comunhão entre pares, entre aqueles que defendem sua tese central ${ }^{18}$. Aqueles que acreditam na esfericidade da Terra são chamados de "globulistas". Interessante notar que, embora tudo isso nos lembre as chamadas "teorias da conspiração", os terraplanistas, em geral, repudiam essa associação.

Uma segunda característica é o que denominamos de "estabelecimento de uma relação bipolar com o conhecimento científico". A ciência é sistema. Portanto, algo a ser criticado e deixado de lado. Afirmou-se, por exemplo, que aquilo que chamamos de ciência nada mais é do que "pseudociência", e que Newton e Einstein não seriam verdadeiros cientistas. Cientistas profissionais são vistos como intolerantes e dogmáticos. Além disso, a ciência contribuiria para o declínio de uma perspectiva religiosa (há relação com o item 5, mais adiante).

Por outro lado, a ciência é referenciada praticamente o tempo todo no discurso de boa parte dos palestrantes, que se utilizam de conceitos, leis, princípios etc. científicos. Abundam termos como energia, eletricidade, magnetismo, fractal, campos, empirismo dentre muitos outros -, provenientes do universo da ciência estabelecida. Valoriza-se, em

\footnotetext{
${ }^{18} \mathrm{Um}$ aspecto curioso que remete a esse sentimento de comunhão e confraternização era um gesto característico que servia como uma espécie de "cumprimento" entre os presentes, com o qual um sujeito, colocando seu antebraço paralelo ao chão e a mão próxima ao coração, simbolizava a "Terra plana".
} 
certa medida, a realização de experimentos na busca do estabelecimento de fatos, algo que costuma estar associado, socialmente, ao fazer científico. Buscam-se evidências em favor da Terra plana o que, também em certa medida, seria oposto ao simples discurso de uma autoridade (religiosa, por exemplo).

Daí, portanto, que a relação com o conhecimento científico pareça oscilar entre dois polos, entre "o amor e o ódio".

Vinculado ao anterior, surge o terceiro item de nossa lista: o uso "particularizado" de termos e conceitos da ciência. Referimo-nos, aqui, ao uso descontextualizado de conceitos científicos, ou seja, o uso fora do contexto das leis e teorias aceitas pela ciência. Nesse terreno, há desde a simples apropriação e uso de um termo ("magnético", p.ex.) que passa a ser associado a fenômenos diversos e heteróclitos, até o estabelecimento de conclusões completamente diversas do pensamento científico, mas com o uso de seus conceitos (p.ex., a afirmação de que é impossível o Sol produzir chamas, pois não possui oxigênio).

Tais afirmações, por vezes, não se limitam a usar conceitos científicos para questionar a própria ciência, mas, antes, denotam um desconhecimento puro e simples do que diz a ciência. Por exemplo, a defesa de que seria impossível sabermos que há hidrogênio e hélio no Sol, uma vez que não se pode colher esse material ${ }^{19}$, mostra um desconhecimento da espectroscopia. A afirmação de que os resultados negativos do experimento de MichelsonMorley "provam" que a Terra é plana mostra uma incompreensão do que foi esse famoso experimento. Nenhuma experiência teria até hoje mostrado que a Terra gira (nesse caso, desconhecimento do pêndulo de Foucault, por exemplo). Embora neguem a gravidade, afirmou-se que a lei de Newton deveria ser testada em um local sem gravidade, mas, como "testar" uma lei que trata da atração entre corpos massivos em um hipotético local em que não haveria essa atração? Algumas informações que até possuem respaldo científico e/ou histórico são apresentadas de modo totalmente descontextualizado, como a ideia de que Newton "não sabia o que era a gravidade", evidenciando o provável desconhecimento da profunda discussão metafísica e filosófica de Newton a esse respeito. Haveria muitos outros exemplos aqui.

A quarta característica é a seletividade no uso de dados e informações. Chama a atenção o fato de que algumas fotos são confiáveis, enquanto outras não são. Por exemplo, fotos tiradas de aviões e de balões, em que não se perceberia a curvatura da Terra, foram apresentadas como evidências em favor do TP, enquanto fotos que mostram a curvatura de nosso planeta eram descartadas como falsas, fruto de montagens, edição digital ou distorção por lentes. Em particular, a ida do homem à Lua é negada com frequência. Mostrou-se uma revista de 1969 em que apareciam desenhos e não fotografias. Afirmou-se que o Brasil, naquele período, era essencialmente rural e as pessoas eram facilmente enganadas, e que ninguém vivo hoje em dia poderia dar um testemunho sobre as expedições à Lua. 19 Diga-se de passagem, essa afirmação torna problemática a informação anterior, de que "não há oxigênio no
Sol". 
Um dado curioso em relação à seletividade e ao uso peculiar de certas imagens, dados e informações foi a apresentação do símbolo da Organização das Nações Unidas (ONU) como sendo um desenho da Terra Plana (ver Fig. 1).

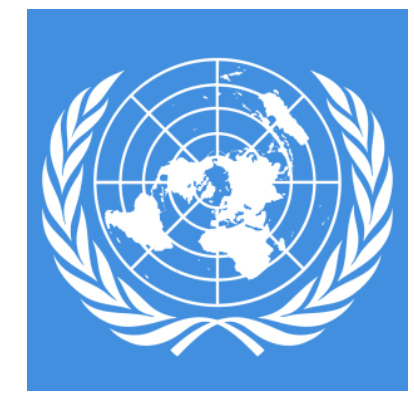

Fig. 1 - Símbolo da ONU. Fonte: https://nacoesunidas.org/

As observações também adquirem, da mesma maneira, esse caráter de seletividade, como fica evidente na célebre experiência do avistamento do navio que se afasta do porto. Foram apresentadas imagens de navios que vão se tornando gradativamente menos nítidos, conforme aumenta a distância do ponto de partida, mas que seriam visíveis "do casco ao alto do mastro", sendo ignoradas imagens que mostrariam o desaparecimento do casco antes do mastro.

Dessa forma, testemunhos, dados, observações, experimentos, fotos e filmagens ora são válidos e confiáveis - se "confirmam" o TP - ora não são.

Um outro exemplo utilizado, e que foi o foco da última palestra do dia, chamava a atenção para uma foto de longa exposição obtida no alto do Monte Kilimanjaro, na África, onde pode-se observar o rastro do movimento estelar do hemisfério norte, com a presença (próximo ao horizonte) da estrela polar. Uma vez que essa estrela não seria visível do hemisfério sul, essa observação foi usada em defesa da planicidade da Terra, ignorando-se a latitude dessa montanha, situada apenas a $3^{\circ} 07^{\prime} \mathrm{S}$, no norte da Tanzânia. A ausência de fotos semelhantes em latitudes mais elevadas do hemisfério sul (ou mesmo ao sopé do Kilimanjaro) foram ignoradas ${ }^{20}$.

Um aspecto importante a destacar, ainda nesse item, é a ausência quase absoluta de dados quantitativos. Poucos valores foram apresentados. Dentre eles, a distância entre o centro da Terra plana e a Antártida, que seria de $40.000 \mathrm{~km}$, e o diâmetro do Sol, estimado em $72 \mathrm{~km}$. Não houve apresentação de como esses valores teriam sido obtidos.

\footnotetext{
20 Link da foto em questão: <https://www.nationalgeographic.com/news/2010/12/101230-space-picturesshuttle-moon-125/>. O título dado à fotografia foi de "As the stars turn" e o texto sobre ela é este: "Star trails create arches over the horizon in a long-exposure picture of the night sky taken from Mount Kilimanjaro in Tanzania. The shot, captured in July and released this week, shows the apparent motion of the stars around Polaris, the star that's almost exactly aligned with Earth's north celestial pole. Also called the North Star, Polaris is the brightest dot in the constellation Ursa Minor. Equatorial regions, such as Kilimanjaro, are the only places on Earth where the celestial poles sit right at the horizon" (grifos nossos).
} 
O vínculo com questões de natureza religiosa (item 5) é uma característica clara do discurso terraplanista, muito embora não estivesse presente na totalidade das palestras. Mas houve palestras específicas sobre esse tema (p.ex., sobre a "Cosmologia das sagradas escrituras") e, mesmo nas demais, não era incomum algum tipo de referência a questões religiosas.

$\mathrm{O}$ aspecto mais óbvio, aqui, é o estabelecimento da relação entre o TP e aquilo que está exposto na Bíblia, particularmente, no livro do Gênesis. A ideia de "domo", de águas inferiores e superiores, é evocada em favor da concepção da Terra plana. Mas há outros elementos importantes. Um deles é a centralidade do homem que, como criação divina, deve situar-se no centro de todo o Universo, que coincide com a posição da Terra. Outras ideias são elencadas para reforçar essa visão, em particular, a noção de que existe um propósito na criação, a própria ideia de criação, assim como a autoridade da Bíblia. Já as concepções científicas, como o Big Bang e o evolucionismo, são trazidas como perspectivas que negam a existência de Deus e gerariam apenas destruição, guerras e desgraças. Afinal, não somos obra do acaso nem poeira de estrelas.

O próximo - e último - item da lista, que tem relações com os itens 1 e 2 , é a crítica à escola e ao ensino de ciências. Foi listado propositadamente em último lugar, pois, é algo que aparece menos explicitamente do que todos os demais itens. Ainda assim, surge com clareza em algumas das falas e tem bastante relevância para a reflexão que nos interessa fazer, na medida em que diz respeito diretamente à educação em ciências.

A escola e o ensino de ciências também são vistos como fazendo parte do "sistema" que aliena e mantém todos na mentira. Tanto uma quanto o outro são vistos como possuidores de um caráter doutrinador. Questionou-se, por exemplo, por que há um globo terrestre nas escolas e por que as evidências em favor da esfericidade da Terra não são apresentadas aos estudantes, desde o ensino fundamental.

Mas há, aqui, um aspecto absolutamente crucial: por diversas vezes foi ressaltado o caráter de simplicidade que o TP tem, ou seja, sua fácil compreensão por qualquer pessoa. Dificuldades com o ensino de ciências, em particular, com a abstração, foram relatadas por alguns palestrantes. Por exemplo, a dificuldade em lidar com termos como 'ano-luz' e com a ideia de escalas e grandes números ("bilhões" de estrelas etc.). A falta de compreensão das aulas de ciências, na escola, era algo compartilhado entre muitos dos presentes.

Um último aspecto merece destaque, embora não diga respeito diretamente ao discurso (registrado em nosso diário de campo) do TP, mas a certas práticas que foram observadas ao longo do evento e que auxiliam na caracterização da perspectiva terraplanista como um todo. Apontamos, aqui, para o próprio formato do evento, composto por um conjunto de apresentações sem direito de manifestação por parte da plateia. Não houve perguntas em nenhum momento. Esse aspecto, somado à proibição da presença da imprensa, destoa das práticas acadêmicas da comunidade científica estabelecida, onde a exposição ao debate e à crítica não apenas faz parte, mas é estimulada, de modo geral. 


\section{Um olhar fleckiano para o TP}

Considerando o TP um fenômeno social contemporâneo, com características e pensamentos próprios que se formam em torno de um grupo com certo fechamento, tencionamos, nessa seção, estudá-lo a partir da teoria do conhecimento de Fleck.

Seria o terraplanismo um estilo de pensamento? Os membros do movimento terraplanista constituem-se em um coletivo de pensamento?

Sim e não. É preciso tomar cuidado, em nossa opinião, com uma associação imediata, por algumas razões. Em primeiro lugar, o TP, em si, nos parece apresentar características de um EP em formação, portanto, ainda em busca da consolidação de certa características que Fleck associa aos EPs, como vimos na seção anterior, tais como a identificação de problemas que interessam e dizem respeito a esse coletivo, os julgamentos e métodos, e um "estilo técnico e literário" próprio. Mas não deixa de ser um EP em instauração. Fleck chega a discutir que há coletivos casuais e momentâneos e os relativamente estáveis ou estáveis. Esses últimos correspondem a grupos socialmente organizados e existentes por um período maior de tempo. A ciência seria um exemplo de CP estável.

Notamos no movimento terraplanista essa busca por coesão na defesa de ideias e argumentos. O próprio slogan do movimento (“a Terra é plana”) representa uma profissão de fé que funciona como um porto seguro a servir de identificação dos seus membros e coesão grupal $^{21}$. Por outro lado, é perceptível que, nessa busca pela formação de um CP e construção de um EP, certas diferenças sejam negligenciadas e contradições passem despercebidas, o que reforça a ideia de um "EP em formação". Chama-nos a atenção, nesse quesito, a relação com a religião, por exemplo. Embora esse seja um aspecto forte no TP, como vimos na seção anterior, não parece ser algo consensual e até parece causar certo desconforto. Algumas palestras da FLAT CON eram exclusivamente sobre aspectos religiosos enquanto outras se esforçavam em situar a discussão da Terra plana no âmbito "científico". Diferenças de interpretação, por exemplo, sobre a estrutura do Sol, se podemos ou não conhecer sua constituição etc., bem como sobre o uso de conceitos científicos, passam despercebidas ou são negligenciadas. Aliás, a própria relação e o uso de conceitos da ciência, que caracterizamos na seção anterior como sendo de "amor e ódio", evidencia que o EP ainda está em busca de sua identidade e de seu "estilo técnico e literário".

Em segundo lugar - e justamente por ser um grupo em formação -, os membros do TP provêm de diversos setores da sociedade, várias camadas sociais, praticam diversas profissões etc. ${ }^{22}$. Diferentemente da ciência, em que a atividade profissional molda o EP/CP

\footnotetext{
21 O próprio gesto da "Terra plana", que chamamos a atenção na nota de rodapé 18 (supra), embora até certo ponto caricato, também vai nessa mesma direção.

22 Nada foi informado ao público sobre os palestrantes, que eram apresentados apenas pelo nome e, em geral, por uma referência ao canal do Youtube que mantinham. Consultas pela internet para obtenção de mais informações profissionais são inconclusivas e incompletas - em função, inclusive, da quantidade de homônimos -, mas indicam formações variadas (advogado, enfermeira, ensino médio etc.). Aparentemente, apenas uma
} 
em si, no caso do TP não se trata disso (pelo menos não nesse estágio). A articulação se dá em torno de uma ideia ("a Terra é plana"). Ao se juntarem nesse coletivo, os membros do movimento terraplanista trazem elementos (pensamentos) de outros coletivos sociais de que participam, promovendo uma espécie de circulação intercoletiva de ideias. Nesse caso, não há a troca direta de ideias entre dois coletivos, mas, na medida em que pessoas de vários coletivos convivem, a circulação intercoletiva ocorre. E essa circulação pode trazer elementos que funcionem como protoideias em um EP terraplanista em formação.

Será preciso certa "acomodação" para que o discurso se afine e diferenças não conciliáveis sejam superadas. Nesse sentido, entra em cena o tráfego intracoletivo, que busca o reforço das formações de pensamento. A FLAT CON nada mais foi que um evento para promover e intensificar esse tráfego intracoletivo, que já ocorria de forma menos organizada e sistemática nas redes sociais (algumas pessoas, no evento, manifestaram claramente a satisfação e empolgação em, finalmente, "conhecer pessoalmente" os demais).

O que trouxemos na seção sobre o pensamento terraplanista, a partir de nossa análise das palestras da FLAT CON, constitui uma primeira aproximação do que pode ser considerado o estilo de pensamento desse coletivo. A relação com o conhecimento científico, o uso de termos e conceitos da ciência, os dados e informações trazidas nas argumentações, o vínculo com questões de natureza religiosa, a crítica à escola e ao ensino de ciências, tudo isso ajuda a compor o quadro que molda esse EP em formação. É interessante também, nesse sentido, a questão da oposição a um "sistema" que esconderia a verdade. Essa procura por "inimigos" - para além da semelhança com as chamadas "teorias da conspiração" - parece ser característica de grupos que buscam identidade própria e coesão.

Esse sentimento de pertencimento e coesão é próprio de um coletivo de pensamento e ajuda a criar o que Fleck denomina de "harmonia as ilusões". O fato de a imprensa haver sido proibida de participar, bem como a proibição da realização de perguntas por parte da plateia (ainda que composta quase totalmente por membros do mesmo $\mathrm{CP}$ ), evidenciam o receio de uma quebra dessa harmonia que estava sendo buscada. Nesse sentido, uma "cola social" importante, para esse grupo, nos pareceu ser o compartilhamento de certa frustação com a escola e o ensino de ciências, por um lado, e a própria projeção social que pertencer ao movimento terraplanista trouxe ou pode trazer (ainda que com o risco do desprezo de outros grupos), por outro. Afinal, pessoas comuns e "ilustres desconhecidos" (como se costuma dizer) ganharam prestígio em redes sociais e estavam ali se apresentando para um público de centenas de pessoas, estavam "sendo vistos". De forma alguma esse elemento pode ser minimizado nessa análise. Ao contrário, parece ser um aspecto central, pois pulsões e afetos estão em jogo nessa problemática tanto quanto argumentos racionais. $O$ conforto explicitamente manifesto por alguns de que a ideia de Terra plana é "uma ideia simples", "que eu compreendo" (e que, por isso, é verdadeira) é um sentimento que atua no reforça do EP.

pessoa possui vínculo com a área de ciências da natureza e currículo na plataforma Lattes (um licenciando em Química). 
Quanto aos círculos esotérico e exotérico, talvez seja demasiado cedo para caracterizá-los em relação ao TP. No entanto, ao menos pelo que se viu nesse evento, fícou claro que foi dado a alguns personagens - em particular os palestrantes convidados - certa proeminência e destaque. Em geral, eram aqueles que tinham maior projeção nas redes sociais na divulgação do TP. Talvez eles componham o germe de um círculo esotérico, em torno do qual vai se formando um conjunto de apoiadores mais anônimos que, embora adeptos do mesmo EP, situam-se no que vai se constituindo como o círculo exotérico.

Um outro ponto que merece atenção, e que articula vários aspectos trazidos anteriormente, é a relação do TP com a ciência e o uso de conceitos da área científica. Aqui está em jogo o tráfego intercoletivo de ideias entre EPs com profundas diferenças que, como aponta Fleck, tende a ser reduzido e produzir desvios de significado. Esses desvios são exatamente o que presenciamos em diversas ocasiões e relatamos na seção descritiva sobre o movimento terraplanista (o uso "particularizado" de termos e conceitos). Como vimos, conceitos são usados de modo descontextualizado e resultados de experimentos (como o de Michelson-Morley e a observação da estrela polar) são interpretados erroneamente, evidenciando desvios de significado. Retirados de seu contexto de origem, termos e expressões ganham novos significados dados pelo coletivo. Aqui entra em jogo também o fato de palavras que compõem o universo da ciência estarem presentes na linguagem cotidiana, o que potencializa esses desvios. A seletividade apontada no uso de dados e informações também se enquadra parcialmente nessa análise, uma vez que, segundo Fleck, problemas importantes para um determinado EP/CP costumam ser considerados irrelevantes para membros de um EP/CP alheio e distante ${ }^{23}$. No caso, pode-se considerar que "a forma da Terra" é o problema central do TP e algo menos relevante para o campo científico (não historicamente, mas atualmente). A seleção de fotos, evidências, experimentos e argumentos feitas pelo CP do TP, ao mesmo tempo em que sinaliza para a existência de desvios de significado, serve para ajudar a criar a harmonia das ilusões interna ao EP.

As diferenças entre o TP e a ciência institucionalizada remetem ao que foi colocado no parágrafo anterior, da dificuldade (ou falta) de diálogo entre esses coletivos. A relação de "amor e ódio" é reflexo dessa dificuldade. Membros do coletivo terraplanista, em certos momentos, lamentam essa ausência de diálogo e colocam a "culpa" nos cientistas, que seriam arrogantes e prepotentes. Outros parecem alimentar essa oposição e desprezar aqueles que consideram adversários, taxando-os de "globulistas", como vimos. De todo modo, essa é uma característica de EPs muito diferentes, segundo Fleck. Diferenças que se expressaram também em certas práticas, como a já destacada ausência da imprensa e do debate, por exemplo. Congressos científicos costumam ser marcados por apresentação de trabalhos e palestras em que se permite e estimula a intervenção da audiência, muitas vezes, levando a um acalorado debate. Também os trabalhos submetidos a eventos e/ou periódicos passam por revisão por

\footnotetext{
23 Inversamente, podemos nos indagar: uma vez que o TP nos é alheio e distante, a que desvios de significado estamos sujeitos?
} 
pares e recebem pareceres. Em relação a isso, apontamos para as práticas relativas à divulgação do TP, baseadas nas redes sociais e, na maioria das vezes, em formato de vídeo. Na ciência, a divulgação das ideias se dá preferencialmente por meio de publicações em uma extensa rede de periódicos que atende a critérios de avaliação rígidos e compartilhados pelo coletivo ${ }^{24}$

Caminhando para o final de nossa breve análise fleckiana do $\mathrm{TP}$, falemos das protoideias. Aqui, certamente, seria preciso aprofundar a pesquisa empírica (histórica, inclusive) para que o vínculo com ideias do passado fosse estabelecido. Nosso estudo não tem esse alcance. Mas algumas coisas podem ser sinalizadas nessa direção. Por exemplo, a relação do TP com a religião certamente traz à tona pensamentos muito antigos e enraizados, e que podem desempenhar a função de "pré-disposições histórico-evolutivas", tais como a ideia de criação divina, do ser humano como centro do universo, entre outras. Nesse sentido, os argumentos históricos em favor da Terra plana, sejam os que existiram desde a antiguidade clássica, sejam os que foram usados contra o heliocentrismo copernicano já mais recentemente, podem estar relacionados a protoideias que influenciam o EP do TP. Aliás, foi interessante notar que uma série de argumentos em favor da Terra plana usados durante a FLAT CON foram argumentos que existiram - e foram superados - ao longo da história da ciência. Em tom um pouco mais especulativo, suspeitamos que outros elementos relacionados a protoideias (e a outros EPs) possam ser objeto de investigação na busca por se compreender o TP, em particular, suas relações com o pensamento conservador ${ }^{25}$.

E o que dizer dos acoplamentos ativos e passivos? O discurso do TP está repleto de desejos que se manifestam na forma de acoplamentos ativos. Mas seria ingênuo de nossa parte desconsiderar os resultados que, aos olhos de seus membros, poderiam ser considerados acoplamentos passivos (p.ex., novamente, o avistamento da estrela polar do hemisfério sul seria um deles). Argumentos usados historicamente, como não sentirmos o movimento da Terra, também poderiam ser arrolados aqui.

De acordo com Fleck, o aprofundamento do conhecimento em uma dada área leva ao aumento tanto dos acoplamentos ativos quanto dos passivos, embora se busque sempre um número maior de acoplamentos passivos, ou seja, resultados inevitáveis a partir de determinadas condições dadas (acoplamentos ativos). Seria importante que o TP se empenhasse na busca por esses acoplamentos passivos ${ }^{26}$. Nessa busca, podem surgir

\footnotetext{
${ }^{24}$ Há muito mais elementos aqui, sem dúvida. Fleck, inclusive, traz uma rica discussão a respeito da produção de conhecimento e circulação de ideias no EP científico, falando da ciência dos periódicos, ciência dos manuais, ciência dos livros didáticos e ciência popular.

25 Só para se ter uma ideia, algumas características do pensamento conservador, segundo Mannheim, seriam o apego ao imediato, ao concreto, e a valorização do passado temporal (MANNHEIM, 1986). Mas a discussão toda de Mannheim, é claro, é muito mais detalhada e complexa do que isso.

26 No início de 2020, um norte-americano de 64 anos, defensor do terraplanismo, lançou-se em um foguete caseiro como parte de um projeto para fotografar a Terra a partir de grandes altitudes e "provar" que ela seria plana. Infelizmente houve outros tipos de "acoplamentos passivos" e o artefato caiu no solo alguns segundos após o lançamento, matando o seu ocupante (ver, p. ex.:
} 
complicações que levem à transformação e ao desenvolvimento do EP. Sem dúvidas que a articulação desse EP deve passar por essa questão. Mas também seria ingênuo achar que existiria uma espécie de "arena neutra" a partir da qual evidências e "fatos" pudessem ser discutidos por esse coletivo e pelo coletivo científico com vistas a determinar "quem está certo". Fleck, certamente, não dá sustentação a esse tipo de pretensão.

\section{Algumas reflexões para o ensino de ciências}

Nosso estudo procurou apresentar uma caracterização do terraplanismo baseada em uma perspectiva oferecida pela epistemologia. Por se tratar de um fenômeno sociocultural que somente ganhou algum destaque recentemente, nos parece razoável afirmar que outros estudos e aprofundamentos virão e, sem dúvida, a partir de diversas perspectivas teóricas e metodológicas. Em particular, acreditamos que a perspectiva da sociologia de Karl Mannheim pode vir a contribuir e complementar, em certo sentido, aquilo que foi exposto nesse trabalho 27 .

O final do último parágrafo da seção anterior já aponta a direção de nossas reflexões finais a partir do estudo empreendido do TP com o referencial de Ludwik Fleck.

Por um lado, consideramos inadequadas e pouco eficientes atitudes de ridicularização do TP e de desprezo desse movimento, principalmente por parte de educadores em ciências ${ }^{28}$. A questão nos parece ganhar novos contornos quando percebemos que, na política brasileira atual, teorias conspiratórias, revisionismo histórico e outros aspectos da pós-verdade rondam as mais altas esferas de poder. O filósofo (sic) considerado "guru" intelectual do governo, por exemplo, não chega a afirmar que a Terra é plana, mas diz que não se pode provar que não seja. Além disso, devemos perguntar: será que todos os professores de ciências estão preparados para explicar aos seus estudantes por que a Terra não é plana e por que devemos dar crédito ao conhecimento cientificamente aceito hoje em dia a esse respeito?

Como fenômeno social e cultural, o TP deve ser objeto de atenção em nossa área. Fleck defendia que a epistemologia fosse considerada "a ciência dos EPs", incorporando em toda sua profundidade as dimensões social e histórica, e promovendo a tolerância entre grupos e pessoas com pensamentos diferentes e, eventualmente, conflitantes. Em particular, em seu artigo de 1960 (que foi publicado somente após sua morte), afirma que "estudos comparados

\footnotetext{
$<$ https:/ciencia.estadao.com.br/noticias/geral,terraplanista-morre-em-lancamento-de-foguete-caseiro-noseua,70003208244>).

27 Além do texto já citado desse autor, o clássico Ideologia e Utopia também seria uma fonte importante nessa direção (MANNHEIM, 1954). Embora Fleck não cite explicitamente Mannheim, atribui-se a esse último a introdução do conceito de "estilo de pensamento" na língua alemã (Denkstil) e, em nossa opinião, o pensamento de ambos os autores dialogam de modo frutífero.

28 Referimo-nos, aqui, tanto a posicionamentos encontrados em redes sociais envolvendo eventuais discussões entre terraplanistas e membros da comunidade científica, quanto a posições assumidas por colegas em conversas informais acerca do TP.
} 
sobre estilos tornarão os estudantes mais tolerantes com estilos estranhos ${ }^{29}$, e os prepararão para a coexistência" (FLECK, 1986b, p. 157, tradução nossa).

Por outro lado, o respeito às diferenças e o reconhecimento do TP como fenômeno social e cultural não significa tratá-lo como equivalente - do ponto de vista epistemológico ao conhecimento cientificamente aceito e historicamente construído ao longo de séculos. Há, quem sabe, certa similaridade ao que ocorreu com as chamadas "concepções alternativas" na área de ensino de ciências que, compreendidas sua constituição e função psicológica em termos de teorias de desenvolvimento cognitivo, mostraram-se um elemento indissociável do processo de ensino e aprendizagem. Essas concepções possuem certa coerência interna e são resistentes à mudança, mas, em última instância, o aprendizado da ciência implica, em algum grau, na superação dessas concepções e, no mínimo, na percepção da existência de contextos de validade e aplicação de concepções científicas e alternativas a elas. Nesse sentido, o TP pode ser visto como em EP em formação que traz em seu bojo um conjunto de concepções que deve ser problematizado pelo ensino das ciências.

Mas a questão nos parece ser mais complexa. Em primeiro lugar, há a questão dos afetos, sinalizada anteriormente. Safatle (2017) nos chama a atenção para a importância dessa dimensão ao lidarmos com o fenômeno da pós-verdade, pois a adesão a um conjunto de ideias - assim como sua defesa e manutenção - não se dá apenas no âmbito do pensamento racional. Aliás, a própria definição do dicionário Oxford de "pós-verdade" (mesmo com todas as críticas que possamos ter a ela) já apontava para isso. De nosso ponto de vista, compromissos epistemológicos e ontológicos dos sujeitos se encontram amalgamados com as dimensões emocional e afetiva, ou seja, os primeiros não podem ser isolados das segundas. Portanto, lidar com o TP, do ponto de vista do ensino de ciências, não é uma tarefa que se circunscreva apenas ao âmbito racional/cognitivo.

Em segundo lugar, pode-se indagar: que ciência devemos apresentar aos estudantes? A ciência dogmática, a ciência como um conjunto de resultados fixos e absolutos, a ciência que cresce por meio de "descobertas" que se acumulam ao logo do tempo, a ciência benevolente e benfeitora da humanidade etc., não contribuem para um diálogo inteligente com o mundo e tampouco servem para desalojar o TP de sua eventual zona de conforto. E, nesse aspecto, concordamos com Lima et al. (2019) de que tanto essa ciência caricata quanto a crítica pós-moderna à ciência podem estar contribuindo para o fenômeno da pós-verdade ${ }^{30}$. É sintomático que os terraplanistas teçam críticas à escola e ao dogmatismo do ensino de ciências, como vimos.

\footnotetext{
29 O termo em inglês é 'strange'. Mas o sentido, aqui, é o de um estilo “alheio".

30 Segundo os autores: "tanto o discurso cientificista (moderno) quanto as principais críticas a ele (incluindo o pós-modernismo) possuem bases metafísicas que são responsáveis por subsidiar a produção e proliferação de "cenários de pós-verdades"” (LIMA et al., 2019, p. 157). A educação em ciências pode reforçar esses cenários e fragilizar a ciência na medida em que a retrate de modo reduzido e simplificado.
} 
O tráfego intercoletivo de ideias pode - e deve - se dar com mais qualidade. Apresentar a ciência em toda sua riqueza histórica e - por que não dizer? - em sua ambivalência, contextualizando histórica e culturalmente as leis, modelos e teorias, discutindo as metodologias próprias do fazer científico em cada campo, problematizando os aspectos éticos e filosóficos da ciência, enfim, dando sentido ao conhecimento, essa é parte da busca do coletivo de educadores em ciências. Mas o ensino crítico da ciência ${ }^{31}$, ao contrário do que alguns podem pensar, não implica em sua desvalorização. Muito pelo contrário. $\mathrm{O}$ obscurantismo é um preço alto demais a pagar pelo relativismo epistemológico.

E aqui nos lembramos do belo mito grego de Prometeu que, tendo roubado o fogo dos deuses para entregar aos homens, lançou sobre si mesmo e sobre a humanidade a ira de Zeus. O titã foi acorrentado ao Cáucaso enquanto seu fígado era dilacerado ao longo dos dias, recuperando-se durante as noites. Aos homens, Zeus enviou Pandora, que os agraciou com todos os males que saíram de sua caixa.

Há várias versões do mito e, sem dúvida, uma miríade de interpretações a seu respeito $^{32}$. Mas esse não é um trabalho sobre mitologia. Interessa-nos, apenas, certas alegorias associadas a essa história. No mito, Prometeu é o criador dos homens que engana Zeus. Ele é ardiloso, astucioso, e sua moral apresenta um caráter ambivalente, de bem e de mal. O fogo é carregado de imagens: é símbolo do conhecimento, do saber, das técnicas, das artes que nos permitem ir além dos outros animais. Também é transformação, trabalho ${ }^{33}$. Nessa história, a apropriação desse conhecimento custou caro aos homens (queriam se equiparar aos deuses?), assim como a curiosidade de Pandora. Houve punição.

A arte e a cultura em geral refletiram as imagens contidas no mito de Prometeu. Com a idade moderna e o Iluminismo, por exemplo, há a associação dessa narrativa com o conhecimento científico e a razão. O saber é luz. O que consideramos como ensino crítico da ciência tem muita relação com as mensagens e alegorias desse mito: a riqueza da ciência, enquanto construção cultural humana, não apaga a sua ambivalência. Mas Prometeu continua sendo um herói, e, se o preço pago pelo conhecimento é o trabalho e a dor, talvez essa seja a condição humana. O conhecimento é o nosso bem mais valioso, e a ciência - com todas as

\footnotetext{
31 Essa perspectiva, certamente, não abriria mão do uso da História, da Filosofia e da Sociologia da Ciência (HFSC). A HFSC possui grande potencial na problematização do TP. É preciso trazer à sala de aula Pitágoras, Aristóteles, Eratóstenes, Copérnico, Galileu, Newton etc., a partir da riqueza histórica de seus trabalhos, como meio problematizador do conhecimento físico e astronômico a ser ensinado, de modo a enriquecê-lo culturalmente e contextualizá-lo. Quem sabe a apresentação, por parte dos professores, do caminho histórico percorrido desde a antiguidade até os dias de hoje em relação ao nosso conhecimento sobre o planeta e sua posição no universo contribua para que os estudantes percebam as razões pelas quais se estabeleceu o conhecimento científico atual. Além disso, argumentos históricos usados contra e a favor dos diversos modelos, contra e a favor da esfericidade da Terra, podem ser resgatados e comparados com argumentos atuais, dando sentido histórico à superação do geocentrismo e da concepção de Terra plana.

32 A esse respeito, ver, por exemplo, Vernant (1990), p. 249-257.

33 Como diz Bachelard: “(...) o fogo é muito mais um ser social do que um ser natural” (BACHELARD, 2008, p. 15 , grifos do autor).
} 
ressalvas que a ela possamos fazer - ainda pode ser vista (como queria Carl Sagan) como uma vela na escuridão ${ }^{34}$.

Eppur si muove...

\section{Referências}

ALBUQUERQUE, A.; QUINAN, R. Crise epistemológica e teorias da conspiração: o discurso anti-ciência do canal "professor terra plana". Mídia e Cotidiano, Rio de Janeiro, v. 13, n. 3, p. 83-104, 2019. doi: https://doi.org/10.22409/rmc.v13i3.38088.

ALVES-MAZZOTTI, A. J.; GEWANDSZNAJDER, F. O método nas ciências naturais e sociais - pesquisa quantitativa e qualitativa. 2. ed. São Paulo: Pioneira, 1999.

BACHELARD, G. A psicanálise do fogo. São Paulo: Martins Fontes, 2008.

COHEN, R.; SCHNELlE, T. (Eds.) Cognition and fact: materials on Ludwik Fleck. Dordrecht: Reidel Publish Company, 1986.

DElizOICOV, D.; CASTILHO, N.; CUTOLO, L. R. A.; DA ROS, M. A.; LIMA, A. M. C. Sociogênese do conhecimento e pesquisa em ensino: contribuições a partir do referencial Fleckiano. Caderno Brasileiro de Ensino de Física, Florianópolis, v. 19, número especial, p. 50-66, mar. 2002. Disponível em:

$<$ http://www.periodicos.ufsc.br/index.php/fisica/article/view/10054/9279>. Acesso em: 20 mai. 2020.

FLECK, L. To look, to see, to know. In: COHEN, R.; SCHNELLE, T. (Eds.) Cognition and fact: materials on Ludwik Fleck. Dordrecht: Reidel Publish Company, 1986a. p. 129-151 [original de 1947].

FLECK, L. Crisis in science. In: COHEN, R.; SCHNELLE, T. (Eds.) Cognition and fact: materials on Ludwik Fleck. Dordrecht: Reidel Publish Company, 1986b. p. 153-158 [original de 1960].

FLECK, L. Gênese e desenvolvimento de um fato científico. Belo Horizonte: Fabrefactum, 2010 .

\footnotetext{
${ }^{34}$ Referimo-nos, nesse ponto, ao conhecido livro de Sagan intitulado "O mundo assombrado pelos demônios - a ciência vista como uma vela no escuro" (SAGAN, 1996). Embora discordemos do "cientificismo" de Sagan, concordamos com sua tese central expressa no subtítulo dessa obra.
} 
LIMA, N. W.; VAZATA, P. A. V.; OSTERMANN, F.; CAVALCANTI, C. J. H.; GUERRA, A. Educação em Ciências nos Tempos de Pós-Verdade: Reflexões Metafísicas a partir dos Estudos das Ciências de Bruno Latour. Revista Brasileira de Pesquisa em Educação em Ciências, v. 19, p. 155-189, 2019. doi: https://doi.org/10.28976/1984-2686rbpec $2019 u 155189$.

LORENZETTI, L.; MUENCHEN, C.; SLONGO, I. I. P. A crescente presença da epistemologia de Ludwik Fleck na pesquisa em educação em ciências no Brasil. Revista Brasileira de Ensino de Ciência e Tecnologia, Ponta Grossa, v. 11, n. 1, p. 373-404, 2018. doi: http://dx.doi.org/10.3895/rbect.v11n1.6041.

LÜDKE, M.; ANDRE, M. E. D. Pesquisa em educação: abordagens qualitativas. São Paulo: EPU, 1986.

MANNHEIM, K. Ideologia e Utopia - Introdução à Sociologia do Conhecimento. 3.ed. Porto Alegre: Globo, 1954.

MANNHEIM, K. O pensamento conservador. In: MARTINS, J. de S. (Org.) Introdução crítica à sociologia rural. 2. ed. São Paulo: Hucitec, 1986, p. 77-131 [Reprodução de MANNHEIM, K. Essays on Sociology and Social Psychology (chapter II: Conservative Thought). London: Routledge and Kegan Paul Ltd., p. 74-119, 1959. Tradução de Sylvia Lyra].

MARTINS, A. F. P. Terraplanismo e Ensino de Ciências: deveríamos estar preocupados?. In: ENCONTRO DE PESQUISA EM ENSINO DE FÍSICA, XVIII, 2020. Atas...

MARTINS, A. F. P. A obra aberta de Ludwik Fleck. Revista Brasileira de Pesquisa em Educação em Ciências (no prelo).

MAYRING, P. Introdução à Pesquisa Social Qualitativa: uma introdução para pensar qualitativamente. 5. ed. Weinheim: Beltz, 2002.

MELO, L. W. S.; PASSOS, M. M.; SALVI, R. F. Análise de Publicações 'Terraplanistas' em Rede Social: Reflexões para o Ensino de Ciências sob a Ótica Discursiva de Foucault. Revista Brasileira de Pesquisa em Educação em Ciências, v. 20, p. 275-294, 2020. doi: http://dx.doi.org/10.28976/1984-2686rbpec2020u275294. 
MORAES, R. Uma tempestade de luz: a compreensão possibilitada pela análise textual discursiva. Ciência \& Educação, Bauru, v. 9, n. 2, p. 191-210, 2003. doi: https://doi.org/10.1590/S1516-73132003000200004.

MORAES, R.; GALIAZZI, M. do C. Análise Textual Discursiva. Ijuí: Ed. Unijuí, 2011.

OXFORD DICTIONARY. Oxford Dictionary 2016 word of the year. Disponível em: $<$ https://www.lexico.com/definition/post-truth>. Acesso em: 18 mai. 2020.

OXFORD LEARNERS'S DICTIONARIES. Post-truth. Disponível em: $<$ https://www.oxfordlearnersdictionaries.com/definition/english/post-truth $>$. Acesso em: 18 mai. 2020.

PIVARO, G. F. A crença numa terra plana e os ambientes virtuais: identificando relações e construções de conhecimento. In: Encontro Nacional de Pesquisa em Educação em Ciências, XII, 2019, Natal. Atas... Disponível em: <http://abrapecnet.org.br/enpec/xii-enpec/anais/ trabalhos.htm>. Acesso em: 20 mai. 2020.

SAFATLE, V. É racional parar de argumentar. In: DUNKER, C. et al. (Orgs.). Ética e Pósverdade. Porto Alegre: Dublinense, 2017. p. 126-136.

SAGAN, C. O mundo assombrado pelos demônios - a ciência vista como uma vela no escuro. São Paulo: Cia das Letras, 1996.

VERNANT, J-P. Mito \& pensamento entre os gregos. Rio de Janeiro: Paz e Terra, 1990. 